\title{
Diagnosis and monitoring of central nervous system involvement in systemic lupus erythematosus: value of F-18 fluorodeoxyglucose PET
}

S M Weiner, A Otte, M Schumacher, R Klein, J Gutfleisch, I Brink, P Otto, E U Nitzsche, E Moser, $\mathrm{H}$ H Peter

\begin{abstract}
Objective-To investigate prospectively abnormalities of brain glucose utilisation in relation to major or minor neuropsychiatric symptoms in systemic lupus erythematosus (SLE).

Methods-Positron emission tomography (PET) using F-18-labelled fluorodeoxyglucose was performed in 28 patients with SLE. Patients were classified as having severe neuropsychiatric manifestations (seizures, focal neurological deficits, acute confusional states, mood disorders) $(n=12)$, or mild neuropsychiatric manifestations (headache, reactive depression, cognitive dysfunction, anxiety disorders) $(n=11)$ and five patients without signs of central nervous system (CNS) involvement. Ten clinically and neurologically healthy volunteers served as controls. In 26 patients magnetic resonance imaging (MRI) was performed and autoantibodies against CNS tissue, ribosomal $P$ protein and cardiolipin were measured. In 14 patients follow up PET scans were performed after a mean (SD) period of $11.6(9.5)$ months.
\end{abstract}

Results-PET scans showed hypometabolism in at least one brain region in all patients with severe or mild CNS symptoms $(100 \%)$ as compared with patients without cerebral symptoms (40\%) $(p<0.0025)$. Parieto-occipital regions were most commonly affected $(96 \%)$, followed by parietal regions (32\%). In contrast, MRI images were abnormal in only 11 of 22 patients $(50 \%)$ with neuropsychiatric symptoms and in one of four patients $(25 \%)$ without symptoms. In 12 of 14 patients examined in follow up PET scans persistence, improvement or worsening of cerebral symptoms were associated with unchanged, decreased or increased brain hypometabolism, respectively. No significant correlation was found between PET or MRI findings and autoantibody profiles.

Conclusions-PET imaging represents a sensitive tool to detect manifest or subclinical CNS involvement in SLE and PET findings correlate well with the clinical course of disease.

(Ann Rheum Dis 2000;59:377-385)

Neuropsychiatric manifestations have a strong impact on morbidity and mortality in systemic lupus erythematosus (SLE). ${ }^{1}$ In SLE, central nervous system (CNS) manifestations have been described in $18-61 \%$ of cases. $^{2-5}$ The diagnosis of cerebral involvement can be difficult and has to be differentiated from neurological complications that result from uraemia, hypertension, drugs or metabolic changes. The pathogenesis of numerous CNS manifestations remains unclear. Immune complex mediated vasculitis might result in infarction, haemorrhage or in altered permeability of the blood brain barrier playing a permissive part in antibody mediated injury. Other neurological symptoms like strokes reflect an ischaemic arteriopathy of small or medium size vessels that may be caused by antiphospholipid antibodies. Finally, several investigators have implicated autoantibodies against ribosomal $\mathrm{P}$ proteins and neurons in the pathogenesis of neuropsychiatric SLE..$^{6-9}$ However, because of a lack of standardisation and commercialisation of test systems, the usefulness of serological methods in the diagnosis of CNS involvement have been discussed controversially. ${ }^{10} \mathrm{Com}-$ puted tomography (CT) or magnetic resonance imaging (MRI) have been found to be useful in the detection of focal neurological deficits rather than diffuse presentations. ${ }^{11-13}$ Studies with single photon emission computed tomography (SPECT) have shown in patients with CNS lupus that functional imaging is more sensitive than morphological imaging such as MRI or CT. ${ }^{14}{ }^{15}$ To date, there exist only few reports on a small number of patients concerning the value of positron emission tomography (PET) in the diagnosis and monitoring of CNS SLE with cerebral involvement. ${ }^{16-19}$ Furthermore, there are conflicting reports regarding the brain regions involved in neuropsychiatric SLE. ${ }^{14} 1819$

The aim of this study was to examine brain glucose utilisation using F-18 fluorodeoxyglucose (FDG) PET in 28 patients with SLE. Twenty three patients had minor or major neuropsychiatric symptoms at entry and five patients had no CNS symptoms at all. Follow up PET examinations were done in 14 patients. The PET data were compared with clinical data, MRI scans and serological findings, including anticardiolipin and anti-CNS antibodies.

Methods

PATIENTS AND CONTROLS

Ten healthy controls (mean (SD) age 40 (12) years, five women, five men) and 28 patients 
Table 1 Clinical and serological parameters in 28 patients with SLE

\begin{tabular}{ll}
\hline Patients with & $n(\%)$ \\
\hline Malar rash & $7(25)$ \\
Discoid rash & $2(7)$ \\
Photosensitivity & $15(54)$ \\
Oral ulcers & $5(18)$ \\
Arthritis/arthralgia & $22(79)$ \\
Serositis & $7(25)$ \\
Renal disorder & $19(68)$ \\
Sicca syndrome & $7(25)$ \\
Haematological disorder & \\
Haemolytic anaemia & $4(14)$ \\
Leucopenia & $9(32)$ \\
Thrombocytopenia & $5(18)$ \\
Antinuclear antibody & $28(100)$ \\
Anti-dsDNA antibody & $20(71)$ \\
Antibodies against extractable nuclear antigens & $21(75)$ \\
Sm & $12(43)$ \\
nRNP & $12(43)$ \\
Ro/SS-A & $13(46)$ \\
La/SS-B & $9(32)$ \\
Ribosomal P & $6(21)$ \\
Low complement haemolytic activity (CH50) & $7(25)$ \\
Increased plasma complement split product C3d & $18+/ 27(67)$ \\
\hline
\end{tabular}

*30.3 (11.9) U/ml (normal range $20-50 \mathrm{U} / \mathrm{ml})$. †15.4 (5.6) mg/l (normal range <10 mg/l).

(mean (SD) age 38 (13) years, 24 women, four men) were studied. All patients met at least four of the American College of Rheumatology (ACR) criteria for the classification of SLE. ${ }^{20}$ The duration of illness ranged from 1 month to 28 years (mean (SD) duration 5.7 (6.5) years). Disease activity was assessed using the SLE Disease Activity Index (SLEDAI) ${ }^{21}$

None of the study participants exhibited anamnestic hints of neurovascular or neurodegenerative disease. Secondary causes such as infection, uraemia, hypertension, drugs and metabolic abnormalities were excluded. One patient with SLE had a history of brain surgery because of neurocytoma three years before the entry in the study. As regards the controls, only participants with normal clinical and neurological findings were included in the study. For the patient group, 23 consecutive patients with clinical and neurological findings indicating disease related CNS involvement were included, as well as five consecutive patients without actual neuropsychiatric complaints. One patient of the latter group had a history of impairment of concentration three years ago. Disease related neuropsychiatric manifestations were defined as abnormalities of neurological function identified by current history and physical examination and noted as a change from a prior state.

The CNS manifestations were classified according to the ACR nomenclature for neuropsychiatric $\mathrm{SLE}^{22}$ and divided into "severe" and "mild" symptoms:

Severe

Aseptic meningitis; focal neurological deficits (because of cerebrovascular disease or demyelinating syndrome); movement disorder (chorea); myelopathy; seizures; acute confusional state; mood disorder (depression); psychosis.

Mild

Headache (including migraine); reactive psychological disturbances; cognitive dysfunction (impairment of attention, concentration, memory or word finding); anxiety disorder.
RADIOPHARMACEUTICALS

All participants were given $370 \mathrm{MBq}$ FDG into a peripheral vein. FDG was synthesised and prepared as reported previously. ${ }^{23}$

PET STUDY PROTOCOL

Before the PET procedure, each study participant had to fast for at least 12 hours and was asked to empty the bladder. Then, patients and controls were put at rest in a quiet room with dim lights, remaining awake with closed eyes during the 10 minute waiting period. After injection of FDG, the probands remained at rest in a horizontal position for another 30 minutes. The head of each test person was positioned parallel to the orbitomeatal line with the aid of a laser beam. To exclude movements during the scanning procedure the head was placed in a moulded thermoplastic head support. All subjects were studied at rest. The acquisition started about 35 minutes after tracer injection. PET imaging was performed on a Siemens CTI ECAT EXACT tomograph. The device records 31 planes simultaneously, which encompass a $10.8 \mathrm{~cm}$ field of view. The spatial resolution is $6.0 \mathrm{~mm}$ full width at half maximum. Photon attenuation was automatically calculated using Siemens-CTI standard software routine. ${ }^{24} \mathrm{~A}$ total of six frames of five minutes duration was acquired. Images were reconstructed using filtered back-projection (Shepp-Logan filter, cut off 0.3 cycles/pixel). For data analysis, summed images were used (summing the dynamically acquired frames 1 to 6 into one image).

Standardised cortical and subcortical elliptical regions of interest (ROIs) were assigned by consensus of two independent investigators to three adjacent transaxial slices of the following regions: frontal, parietal, occipitofrontal, temporolateral, temporomedial, parieto-occipital, thalamus, putamen, caudate nucleus, cerebellar (mean of lateral and dorsal cerebellum), brain stem, global at the level of the thalamus and basal ganglia.

Shape and size of ROIs were the same in all patients and controls, as the ROI templates were copied into the corresponding planes of each study. Shape and size were fitted to actual head form by computer simulation. The position of all ROIs was adjusted to the corresponding anatomical localisation. In each ROI, the average uptake per pixel per time was determined.

ROI analysis was performed using a SUN sparc station and SUNVIEW software. To allow inter-individual comparisons, regional cerebral metabolism was normalised by global glucose metabolism (glucose metabolic index, GMI; GMI=ROI uptake/global uptake) determined from the global brain ROI at the level of the thalamus and basal ganglia. All images were interpreted by the blinded observers.

MRI

MRI scanning of brain was performed with a $1 . O$ resp. 1.5 tesla MR imager system (Magnetom Expert and Magnetom Vision, Siemens, Erlangen, Germany), including T2 and T1 weighted spin-echo and inversion recovery 
sequences. Biplanar and triplanar views were used with slice thickness varying between 4 $\mathrm{mm}$ to $10 \mathrm{~mm}$. In 21 of 26 patients paramagnetic contrast medium (Gd-DTPA) was administered intravenously. MR images were examined by a neuroradiologist (MS) for the presence of atrophy, focal and diffuse lesions. All images were interpreted by the blinded observer.

IMMUNOLOGICAL TESTS

Commercially available slides with fixed HEp-2 cells (Kallestad Laboratory) were used to screen the patient sera (starting dilution
1:50) for ANAs of the IgG class. Antibodies against extractable nuclear antigens (ENA) were measured using a commercially available ENA Immunoblot (Innogenetics NV, Belgium). Anti-ds DNA antibodies were measured using the Crithidia luciliae method. Anticardiolipin antibodies (aCL) of IgG and IgM isotype were detected by ELISA (Synelisa, Cardiolipin antibodies, Pharmacia). Complement haemolytic activity (CH50) was determined by complement induced haemolysis of IgG coated sheep erythrocytes using a microtitration method. C3d, a marker for intravascular complement turnover and SLE disease activity,

Table 2 Neurospychiatric symptoms, PET and MRI findings in 28 patients with SLE

\begin{tabular}{|c|c|c|c|c|c|c|c|}
\hline $\begin{array}{l}\text { Patient } \\
\text { no/sex/ } \\
\text { age }\end{array}$ & Diagnosis & $\begin{array}{l}\text { Disease } \\
\text { duration } \\
(y)\end{array}$ & $\begin{array}{l}\text { SLEDAI* } \\
\text { score }\end{array}$ & Actual CNS symptoms & Treatment & $\begin{array}{l}\text { PET findings (hypometabolism }>1 \\
\text { SD below controls) }\end{array}$ & MRI findings \\
\hline \multicolumn{8}{|c|}{ Severe neurospychiatric symptoms } \\
\hline $1 / \mathrm{f} / 20$ & SLE & 8 & 29 & $\begin{array}{l}\text { headache, depression, memory } \\
\text { impairment }\end{array}$ & S,A & $\begin{array}{l}\text { parieto-occipital B, } \\
\text { occipito-frontal B, } \uparrow \text { metabolism } \\
\text { caudate nucleus B }\end{array}$ & Normal \\
\hline $2 / \mathrm{m} / 54$ & SLE & 1 & 0 & $\begin{array}{l}\text { severe impairment of memory } \\
\text { and concentration, amaurosis } \\
\text { fugax attacks, oscillopsia }\end{array}$ & none & parieto-occipital B, parietal $\mathrm{R}$ & Mild atrophy \\
\hline $3 / f / 22$ & SLE & 1 & 15 & $\begin{array}{l}\text { psychomotorous unrest, } \\
\text { obsessive-compulsive neurosis, } \\
\text { temporal lobe epilepsy due to } \\
\text { neurocytoma right (state after } \\
\text { brain surgery) }\end{array}$ & S & $\begin{array}{l}\text { parieto-occipital L, parietal } \mathrm{R}>\mathrm{L} \text {, } \\
\text { frontal } \mathrm{B} \text {, basal ganglia } \mathrm{R}, \\
\text { temporal R (surgery) }\end{array}$ & $\begin{array}{l}\text { Mild atrophy, defect temporal } \mathrm{R} \\
\text { (surgery) }\end{array}$ \\
\hline $4 / f / 53$ & $\begin{array}{l}\text { SLE, } \\
\text { TTP, } \\
\text { SAPL }\end{array}$ & 11 & 13 & $\begin{array}{l}\text { stroke on the right, vertigo, } \\
\text { hypogeusia }\end{array}$ & $\begin{array}{l}\mathrm{S}, \mathrm{bC} \\
(\mathrm{n}=2), \mathrm{PL}\end{array}$ & $\begin{array}{l}\text { parieto-occipital R, parietal R, } \\
\text { basal ganglia R, cerebellar L } \\
\text { (diaschisis) }\end{array}$ & $\begin{array}{l}\text { Multiple infarcts parieto-occipital } \\
\text { R, temporal R, cerebellar R, } \\
\text { multiple SFL-R }>\text { L (10 mm), } \\
\text { moderate atrophy }\end{array}$ \\
\hline $5 / f / 46$ & SLE & 0.5 & 17 & $\begin{array}{l}\text { vertigo, gait disturbance, } \\
\text { headache, depression }\end{array}$ & $\mathrm{S}, \mathrm{bC}(\mathrm{n}=1)$ & $\begin{array}{l}\text { parieto-occipital R, praecentral R, } \\
\text { latero-frontal L, occipital L, } \\
\text { cerebellar B }\end{array}$ & $\begin{array}{l}\text { Multiple infarcts } \\
\text { parieto-occipital,frontal -R, } \\
\text { multiple SFL-L ( } 2 \mathrm{~mm}) \text {, moderate } \\
\text { atrophy }\end{array}$ \\
\hline $6 / f / 36$ & SLE & 0.3 & 18 & $\begin{array}{l}\text { headache, vertigo, relapsing } \\
\text { diplopia }\end{array}$ & $\mathrm{S}$ & parieto-occipital B & Normal \\
\hline $7 / \mathrm{f} / 37$ & SLE & 10 & 21 & $\begin{array}{l}\text { memory impairment, common } \\
\text { migraine, depression, } \\
\text { paraesthesia }\end{array}$ & $\mathrm{S}, \mathrm{I}$ & parieto-occipital B & Multiple SFL-R,L (5 mm) \\
\hline $8 / \mathrm{f} / 71$ & SLE & 2 & 37 & $\begin{array}{l}\text { hypomanic syndrome, } \\
\text { impairment of attention, mental } \\
\text { aberration }\end{array}$ & $\mathrm{S}, \mathrm{bC}(\mathrm{n}=1)$ & parieto-occipital B & Normal \\
\hline $9 / f / 39$ & $\begin{array}{l}\text { SLE, } \\
\text { sAPL }\end{array}$ & 3 & 5 & diplopia & none & parieto-occipital B, parietal B & Mild atrophy \\
\hline $10 / f / 31$ & SLE & 1 & 23 & $\begin{array}{l}\text { vertigo, disorder of eye } \\
\text { movement, acute confusional } \\
\text { state }\end{array}$ & S,I & parieto-occipital B & Normal \\
\hline $11 / f / 29$ & SLE & 5 & 0 & $\begin{array}{l}\text { athymia, history of infarction } 4 \\
\text { years ago }\end{array}$ & $\mathrm{S}, \mathrm{H}$ & $\begin{array}{l}\text { patchy uptake pattern, } \\
\text { parieto-occipital B, parietal B, } \\
\text { temporal B }\end{array}$ & $\begin{array}{l}\text { Multiple infarcts temporal R, } \\
\text { multiple SFL frontal, } \\
\text { temporo-occipital L }\end{array}$ \\
\hline $12 / f / 32$ & SLE & 1 & 10 & visual disturbance & none & $\begin{array}{l}\text { parieto-occipital B, frontal R, } \\
\text { anterofrontal R }\end{array}$ & $\begin{array}{l}\text { Multiple confluent SFL } \\
\text { fronto-parietal } \mathrm{R}>\mathrm{L}\end{array}$ \\
\hline \multicolumn{8}{|c|}{ Mild neuropsychiatric symptoms } \\
\hline $13 / \mathrm{m} / 30$ & SLE & 0.1 & 29 & headache & $\mathrm{S}, \mathrm{bC}(\mathrm{n}=1)$ & parieto-occipital B & Normal \\
\hline $14 / f / 20$ & SLE & 0.3 & 32 & headache & none & $\begin{array}{l}\text { parieto-occipital B, temporal B, } \\
\text { cerebellar B }\end{array}$ & Multiple SFL-L (4 mm) \\
\hline $15 / \mathrm{m} / 35$ & SLE & 0.3 & 22 & $\begin{array}{l}\text { headache, impairment of } \\
\text { concentration }\end{array}$ & $S$ & parieto-occipital B, cerebellar B & ND \\
\hline $16 / f / 31$ & SLE & 11 & 4 & $\begin{array}{l}\text { reactive depression, anxiety, } \\
\text { vertigo }\end{array}$ & $\mathrm{S}, \mathrm{oC}$ & parieto-occipital B, parietal B & Normal \\
\hline $17 / \mathrm{f} / 41$ & SLE & 7 & 1 & impairment of concentration & S,oC & parieto-occipital B & Mild cerebellar atrophy \\
\hline $18 / \mathrm{f} / 27$ & SLE & 1.8 & 6 & memory impairment & $\mathrm{S}, \mathrm{A}$ & parieto-occipital $\mathrm{L}>\mathrm{R}$ & Normal \\
\hline $19 / \mathrm{f} / 35$ & SLE & 4 & 14 & common migraine & $\mathrm{s}$ & parieto-occipital B & Normal \\
\hline $20 / f / 34$ & SLE & 2.7 & 23 & headache & $\mathrm{S}, \mathrm{bC}(\mathrm{n}=6)$ & parieto-occipital B, parietal B & Normal \\
\hline $21 / f / 32$ & SLE & 3 & 6 & impairment of attention, tinnitus & S & parieto-occipital B & Normal \\
\hline $22 / f / 47$ & SLE & 8 & 8 & $\begin{array}{l}\text { common migraine, scintilating } \\
\text { scotoma, impairment of } \\
\text { memory }\end{array}$ & S & parieto-occipital B & Multiple SFL-R>L (2 mm) \\
\hline $23 / \mathrm{f} / 42$ & SLE & 15 & 6 & impairment of memory & $\mathrm{S}, \mathrm{H}$ & parieto-occipital R, parietal B & Normal \\
\hline \multicolumn{8}{|c|}{ No neuropsychiatric symptoms } \\
\hline $24 / \mathrm{f} / 53$ & SLE & 28 & 0 & none & $\mathrm{S}$ & parieto-occipital L & Normal \\
\hline $25 / f / 18$ & SLE & 5 & 0 & $\begin{array}{l}\text { none, history of impairment of } \\
\text { concentration } 3 \text { years ago }\end{array}$ & $\mathrm{H}$ & cerebellar B & Few SFL-L (2 mm) \\
\hline $26 / \mathrm{m} / 70$ & SLE & 19 & 4 & none & $\mathrm{S}$ & normal & ND \\
\hline $27 / f / 45$ & SLE & 6 & 11 & none & $\mathrm{S}$ & normal & Normal \\
\hline $28 / f / 37$ & SLE & 4 & 8 & none & S,oC & normal & Normal \\
\hline
\end{tabular}

$\mathrm{S}=$ corticosteroids, $\mathrm{bC}=$ bolus cyclophosphamide (number of boli) $\mathrm{oC}=$ oral cyclophosphamide, $\mathrm{A}=$ azathioprine, $\mathrm{H}=$ hydroxychloroquine/chloroquine, $\mathrm{PL}=$ plasmapheresis, $\mathrm{I}=$ intravenous immunoglobulins, $\mathrm{L}=$ left, $\mathrm{R}=$ right, $\mathrm{B}=$ both, $\mathrm{PET}=$ positron emission tomography, $\mathrm{MRI}=$ magnetic resonance imaging, $\mathrm{ND}=$ not done, $\mathrm{SFL}=$ a small focal area of increased signal on T2 weighted images present in white matter, TTP $=$ thrombocytic thrombocytopenic purpura, SLE

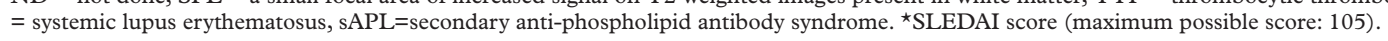


Table 3 Summary of cerebral MRI and PET findings in patients with or without neuropsychiatric symptoms

\begin{tabular}{lll}
\hline Patients with & $\begin{array}{l}\text { Pathological MRI } \\
\text { findings (\%) }\end{array}$ & $\begin{array}{l}\text { Pathological PET } \\
\text { findings (\%) }^{*}\end{array}$ \\
\hline $\begin{array}{l}\text { Severe neuropsychiatric symptoms } \\
\text { Mild neuropsychiatric symptoms }\end{array}$ & $8 / 12(67)$ & $12 / 12(100)$ \\
No neuropsychiatric symptoms & $3 / 10(30)$ & $11 / 11(100)$ \\
\hline
\end{tabular}

${ }^{\star}$ Brain glucose hypometabolism $>1 \mathrm{SD}$ below normal control values.

was measured as previously described..$^{25}$ AntiCNS antibodies of IgG and IgM isotype were measured by ELISA, using a $100000 \mathrm{~g}$ supernatant prepared from beef brain by a standard method. ${ }^{9}$

STATISTICAL ANALYSIS

Statistical analysis was performed using Fisher's exact test and the Mann-Whitney U test. $p$ Values less than 0.05 were considered as statistically significant. All PET data are expressed as mean (SD).

\section{Results}

INITIAL CLINICAL AND MRI FINDINGS

Table 1 shows the clinical and serological parameters observed in the 28 SLE patients. Treatment at entry consisted of chloroquine/ hydroxychloroquine with or without corticosteroids in three patients, pulse cyclophosphamide with corticosteroids in five patients, oral cyclophosphamide and corticosteroids in three patients, azathioprine and corticosteroids in two patients, corticosteroids alone in 11 patients. Four patients were untreated.

Twelve patients exhibited at least one "severe" neuropsychiatric symptom, 11 patients had one to three "mild" symptoms, present at the time of PET and MRI examination (table 2). Neuropsychiatric symptoms were cognitive dysfunction $(n=11)$, persistent headache $(n=7)$, vertigo $(n=5)$, mood disorder $(n=5)$, severe visual disturbance $(n=4)$, common migraine $(n=3)$, acute confusional state $(n=2)$, scintillating scotoma $(n=1)$, tinnitus $(n=1)$, reactive depression $(n=1)$, stroke $(n=1)$, gait disturbance $(n=1)$, paraesthesia $(n=1)$, hypogeusia $(n=1)$, anxiety disorder $(n=1)$ and obsessive-compulsive neurosis $(n=1)$. The total prednisone dose in symptomatic patients was 18.0 (14.8) $\mathrm{mg}$ (range 0 to $50 \mathrm{mg}$ ) and in asymptomatic $9.6(9.4) \mathrm{mg}$ (range 0 to $25 \mathrm{mg}$ ) per day. The mean SLEDAI score was 15.6 $(\mathrm{SD}=11.1$; range 0 to 37$)$ in lupus patients with severe neuropsychiatric symptoms, 13.7 $(\mathrm{SD}=10.9$; range 1 to 32$)$ in patients with mild cerebral symptoms and $4.6(\mathrm{SD}=4.87$; range 0 to 11 ) in asymptomatic patients.

MRI showed abnormal findings in 8 of 12 patients $(67 \%)$ with major neuropsychiatric symptoms, in 3 of 10 patients with minor neuropsychiatric symptoms $(30 \%)(\mathrm{p}=1.0, \mathrm{NS})$ and in 1 of 4 patients $(25 \%)$ without neuropsychiatric symptoms. Overall, cerebral infarcts were found in three patients, focal areas of increased signal on T2 weighted images in white matter in eight patients, mild or moderate brain atrophy in six patients. Gadolinium enhancement of focal lesions was present only in one patient (patient 12).

\section{INITIAL BRAIN PET FINDINGS}

Significant hypometabolism was assumed if GMI values lay more than one standard deviation below normal control values. Evaluation of metabolic pattern in brain PET showed hypometabolism in at least one ROI of all patients with severe or mild CNS symptoms. In these patients, GMI values ranged at least in

Table 4 Follow up neuropsychiatric and PET findings in 13 patients with and one patient without initial symptoms (patient 28)

\begin{tabular}{|c|c|c|c|c|c|c|}
\hline $\begin{array}{l}\text { Patient } \\
\text { no }\end{array}$ & Diagnosis & $\begin{array}{l}\text { SLEDAI* } \\
\text { score }\end{array}$ & $\begin{array}{l}\text { Time } \\
\text { period after } \\
\text { initial PET } \\
\text { (months) }\end{array}$ & CNS symptoms & Treatment & Follow up PET findings \\
\hline 1 & SLE & 2 & 10 & $\begin{array}{l}\text { complete regression (depression, headache, } \\
\text { memory impairment) }\end{array}$ & intensified: $S, b C(n=7)$ & $\begin{array}{l}\text { parieto-occipital and nucleus caudatus } \\
\text { normalised, occipito-frontal unchanged }\end{array}$ \\
\hline \multirow[t]{2}{*}{2} & SLE & 0 & 4 & $\begin{array}{l}\text { improved (impairment of concentration and } \\
\text { memory) } \\
\text { unchanged (amaurosis fugax attacks, } \\
\text { oscillopsia) }\end{array}$ & first introduced: S, oC & $\begin{array}{l}\text { parieto-occipital B normalised } \\
\text { parietal R improved }\end{array}$ \\
\hline & & 0 & 9 & worsened (impairment of concentration) & unchanged to month 4 & $\begin{array}{l}\text { parieto-occipital } \mathrm{B} \text { and parietal } \mathrm{R} \text { worsened } \\
\text { again }\end{array}$ \\
\hline 3 & SLE & 5 & 2 & $\begin{array}{l}\text { improved (psychomotorous unrest, } \\
\text { obsessive-compulsive neurosis) }\end{array}$ & intensified: $S, b C(n=3)$ & $\begin{array}{l}\text { parietal B and frontal B normalised, parietal } \\
\text { R unchanged }\end{array}$ \\
\hline 4 & SLE & 8 & 13 & $\begin{array}{l}\text { improved (stroke) } \\
\text { worsened (headache, impairment of } \\
\text { concentration and memory) }\end{array}$ & reduced: $\mathrm{S}$ & $\begin{array}{l}\text { parietal } \mathrm{R} \text {, parieto-occipital } \mathrm{R} \text {, basal ganglia } \\
\mathrm{R} \text { and temporal } \mathrm{R} \text { worsened }\end{array}$ \\
\hline 5 & SLE & 9 & 30 & $\begin{array}{l}\text { improved (depression) } \\
\text { unchanged (vertigo, gait disturbance, } \\
\text { headache) }\end{array}$ & reduced: $S, A$ & unchanged \\
\hline 6 & SLE & 1 & 3 & $\begin{array}{l}\text { complete regression (vertigo, headache) } \\
\text { unchanged (relapsing diplopia) }\end{array}$ & intensified: $\mathrm{S}, \mathrm{A}$ & unchanged \\
\hline 7 & SLE & 16 & 33 & $\begin{array}{l}\text { complete regression (headache, depression, } \\
\text { paraesthesia) } \\
\text { unchanged (impairment of memory) }\end{array}$ & unchanged: S & unchanged \\
\hline 13 & SLE & 18 & 10 & improved (headache) & intensified: $S, b C(n=6)$ & normalised \\
\hline 14 & SLE & 4 & 5 & improved (headache) & first introduced: S, CyA & normalised \\
\hline 15 & SLE & 7 & 5 & $\begin{array}{l}\text { improved (impairment of concentration) } \\
\text { complete regression (headache) }\end{array}$ & intensified: $S, b C(n=6)$ & normalised \\
\hline 16 & SLE & 4 & 9 & $\begin{array}{l}\text { complete regression (reactive depression, } \\
\text { anxiety, vertigo) }\end{array}$ & $\begin{array}{l}\text { changed from } S, o C \text { to } \\
S, b C(n=6)\end{array}$ & normalised \\
\hline 17 & SLE & 0 & 5 & improved (impairment of concentration) & Reduced: $\mathrm{S}$ & parieto-occipital B slightly improved \\
\hline 18 & SLE & 4 & 24 & complete regression (memory impairment) & Unchanged: S, A & $\begin{array}{l}\text { parieto-occipital } \mathrm{R} \text { unchanged } \\
\text { parieto-occipital L normalised }\end{array}$ \\
\hline 28 & SLE & 2 & 13 & none & Reduced: S & unchanged (normal) \\
\hline
\end{tabular}

^SLEDAI score (maximum possible score: 105). Abbreviations as in table 2 . 


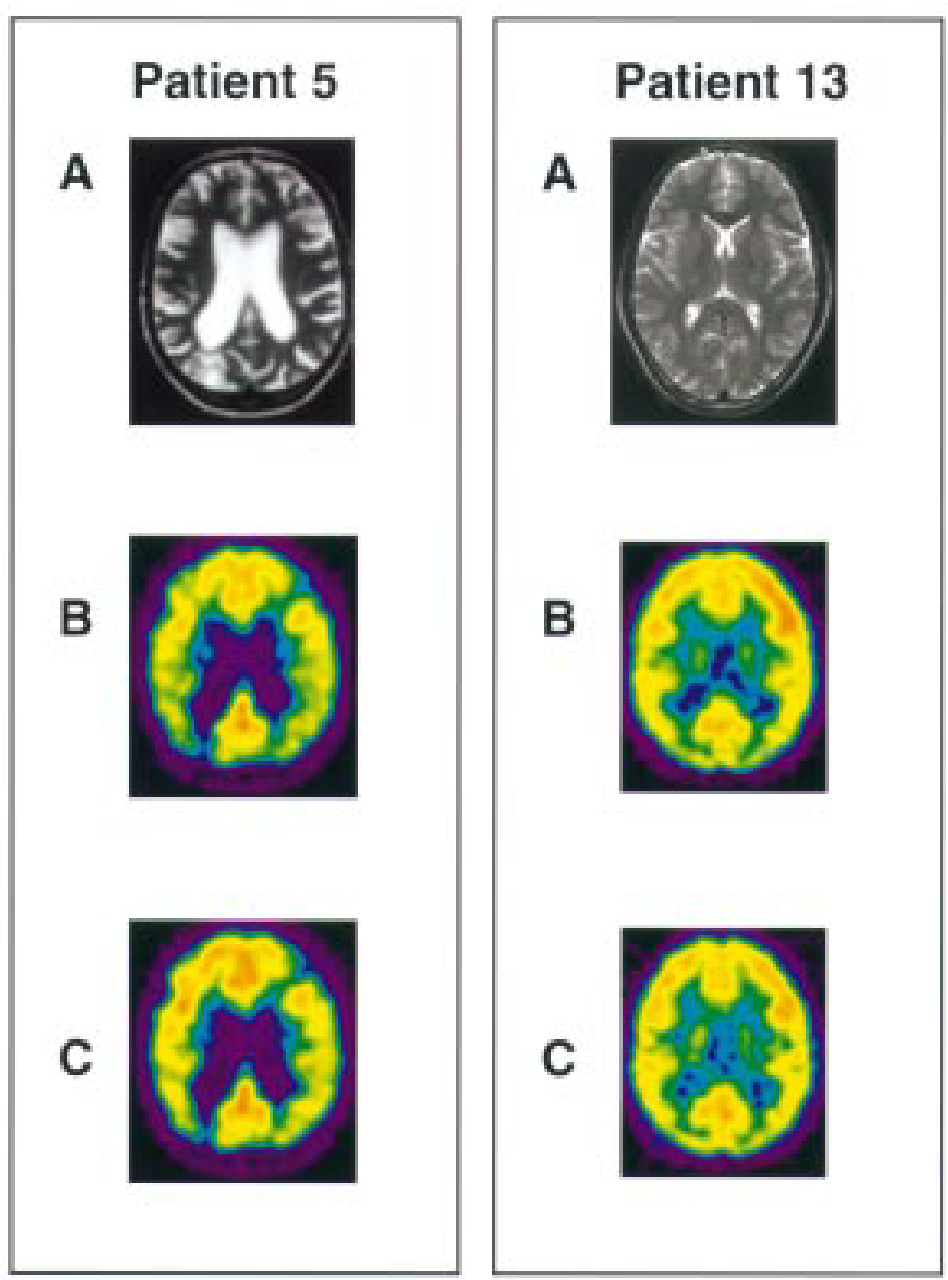

Figure 1 Left panel: FDG-PET and MRI studies in a 46 year old women with SLE and vertigo, gait disturbance, headache and depression (patient 5). (A) An axial T2 weighted MRI scan demonstrated infarction parieto-occipital right and brain atrophy. (B) Initial FDG-PET showed glucose hypometabolism parieto-occipital right, occipital and laterofrontal left. (C) After 30 months vertigo, gait disturbance and headache persisted, but depression improved. Follow up FDG-PET showed nearly unchanged glucose uptake defects. The right image side represents the left brain side. Right panel: FDG-PET and MRI studies in a 30 year old male patient with SLE and headache (patient 13). (A) MRI scan was normal. (B) Inital FDG-PET image showed a significant reduction in glucose metabolism in the parieto-occipital region on both sides. (C) Ten months later the headache had improved. Follow up FDG-PET showed a normalised glucose utilisation (within 1 standard deviation of normal controls) in the previously affected brain regions.

one region two standard deviations below normal control values. In patients without cerebral symptoms, hypometabolism was present in two patients, one of them had a history of cognitive disorder three years before admission. In patients with abnormal PET findings parietooccipital regions (on the right and/or left side) were most commonly affected (24 of $25,96 \%$ ), followed by parietal ( 8 of $25,32 \%$ ), cerebellar ( 5 of $25,20 \%$ ) and frontal regions (4 of 25, $16 \%)$. Other regions were rarely involved. In one patient parieto-occipital hypometabolism was combined with a patchy uptake pattern over the whole brain in accordance with multiple infarcts found in MRI scans (patient 11). In patients with severe neuropsychiatric symptoms, multiple brain regions were not more frequently involved than in patients with mild symptoms ( 8 of $12,66 \%$ versus 5 of $11,45 \%$ ). In symptomatic patients, at least two brain regions (left side, right side or different areas) showed hypometabolism and cerebellar regions were always accompanied. In two asymptomatic, PET positive patients hypometabolism was restricted to one region only, either the left parieto-occipital region or the cerebellum. Table 3 summarises the results of MRI and PET findings.

FOLLOW UP CLINICAL AND BRAIN PET FINDINGS All patients were clinically monitored for a mean (SD) period of 15 (8) months. Interestingly, in two patients (patient 1 and patient 8 ) with initially pathological brain PET and inconspicuous MRI scan, the CNS condition worsened in the follow up period and the MRI scans became pathological after 2 and 10 months, respectively.

Follow up PET examinations were performed in 13 patients with initially pathological findings and in one patient with initially normal brain PET; the follow up periods ranged from 2 to 33 months (table 3 ). Patient 2 had two follow up PET examinations.

Patients with regression or improvement of all CNS symptoms $(n=8)$ also showed improvement or normalisation of brain PET findings in all cases (fig 1). In patients with persistent neuropsychiatric symptoms $(n=4)$ hypometabolism was unchanged $(n=3)$ (fig 1) or partially normalised $(n=1)$. Both patients with worsening of particular cerebral symptoms, PET examination also worsened in the affected brain regions (patients 2 and 4 ).

In patients with intensified or newly introduced immunosuppressive treatment $(n=7)$, the pathological brain PET findings were improved or normalised in six and unchanged in one patient. Patients with unchanged treatment $(n=3)$ showed worsened, improved or unchanged PET scan results. In patients in whom immunosuppressive treatment was reduced $(n=3)$, brain PET findings worsened, did not change or improved. Patient 16 showed normalisation of brain PET after change from oral to intravenous cyclophosphamide.

The mean SLEDAI score was 15.3 (SD = 10.5) at initial PET evaluation and $5.7(\mathrm{SD}=$ 5.5) at the follow up visit. The reduction in the SLEDAI score was higher in patients with intensified (mean reduction of SLEDAI score 15.4 (9.8)) compared with unchanged or reduced immunosuppressive treatment (mean reduction of SLEDAI score 3.8 (2.9); $\mathrm{p}=0.01$ ). PET findings were not related to the SLEDAI score. Thus, a worsened hypometabolism occurred in one patients with a SLEDAI score of 0 .

\section{SEROLOGICAL FINDINGS}

Table 5 depicts the frequency of anti-ribosomal $\mathrm{P}$, anti-CNS and aCL antibodies in the three patient groups. Antibodies against CNS tissue were found in nine patients $(75 \%)$ with severe neuropsychiatric symptoms, in three patients $(27 \%)$ with mild symptoms ( $p=0.039$ versus patients with severe symptoms) and none of the patients without neuropsychiatric symptoms $(p=0.009$ versus patients with severe symptoms). In contrast, aCL or ribosomal $\mathrm{P}$ protein antibodies were not significantly associated 
Table 5 Frequency of antibodies against ribosomal $P$ protein, cardiolipin and CNS tissue in patients with or without neuropsychiatric symptoms

\begin{tabular}{llll}
\hline Patients with & $\begin{array}{l}\text { Anti-ribosomal P } \\
\text { antibodies }\end{array}$ & $\begin{array}{l}\text { Anti-CNS } \\
\text { antibodies }\end{array}$ & $\begin{array}{l}\text { Anti-cardiolipin } \\
\text { antibodies }\end{array}$ \\
\hline Total $(\mathrm{n}=28)$ & $6(21 \%)$ & $12(42 \%)$ & $14^{\star}(50 \%)$ \\
Severe neuropsychiatric symptoms $(\mathrm{n}=12)$ & $3(25 \%)$ & $9(75 \%)$ & $7(58 \%)$ \\
Mild neuropsychiatric symptoms $(\mathrm{n}=11)$ & $3(27 \%)$ & $3(27 \%)$ & $4(36 \%)$ \\
No neuropsychiatric symptoms $(\mathrm{n}=5)$ & 0 & 0 & $3(60 \%)$ \\
\hline
\end{tabular}

${ }^{\star}$ Anti-cardiolipin antibodies consisted only of IgG isotype in eight patients, of IgG and IgM isotype in two patients and only of IgM isotype in four patients.

with the presence of neuropsychiatric symptoms. However, psychiatric symptoms were observed in four of six patients with antibodies against ribosomal $\mathrm{P}$ protein (mood disorder in two patients, reactive depression and anxiety in one patient, obsessive-compulsive neurosis in one patient) and 3 of 22 patients without antiribosomal $\mathrm{P}$ antibodies (mood disorder in three patients $)(p=0.02)$. Of eight patients with focal MRI lesions, six had increased aCL at any time $(75 \%)$ compared with 8 of 18 patients without focal MRI lesions $(44 \%)(p=0.21 ; \mathrm{NS})$. Two of three patients with territorial infarction in MRI showed strongly raised aCL. Overall, no statistically significant relation was found between antibodies against CNS tissue, cardiolipin or ENA and MRI or PET findings.

At entry into the study, C3d levels were increased in 14 of 22 patients clinically diagnosed as having CNS involvement and in four of five patients without neurological symptoms. In patients with pathological brain glucose utilisation the $\mathrm{C} 3 \mathrm{~d}$ levels were not significantly different from patients with normal PET scans. This lack of correlation between C3d plasma levels and PET scan abnormalities held also true in follow up examinations.

\section{Discussion}

The diagnosis of CNS involvement in connective tissue diseases may be problematic and has to be differentiated from neurological impairment attributable to infections, uraemia, hypertension, drug toxicity. SLE patients with focal deficits are more likely to show MRI abnormalities than SLE patients with diffuse presentations. ${ }^{11}{ }^{12}$ Furthermore, MRI analyses did not provide any additional clinical information on cognitively impaired SLE patients. ${ }^{13}$ In the past decade functional imaging has been proved to be more sensitive than morphological imaging. Different methods were used to measure brain function: cerebral blood flow measurement using a xenon-133 inhalation method, ${ }^{26}{ }^{27}$ technetium-99m-hexamethylpropylene amine oxime (HMPAO) ${ }^{14} 152829$ or iodine-123-iodoamphetamine SPECT, ${ }^{30}$ glucose utilisation using fluorine-18 fluorodeoxyglucose (FDG) PET $^{17} 1831$ and magnetic resonance spectroscopy. ${ }^{32}$ The clinical value of SPECT in diagnosing cerebral lupus is being discussed controversially: some studies showed much greater sensitivity than specificity for CNS involvement; others found multifocal areas of cerebral blood flow defects also in asymptomatic cases. ${ }^{15} 3033$

Glucose metabolism measured in PET scans provided a higher resolution and has been shown to be more sensitive than perfusion data obtained by SPECT in several diseases other than SLE. ${ }^{34}{ }^{35}$ Earlier PET studies involving only few patients showed pathological changes in accordance with the clinical state. ${ }^{17}{ }^{36}$ These and most following studies focused exclusively on manifest and severe CNS involvement with positive MRI scans. ${ }^{17} 3637$ However, in recent studies hypometabolism in FDG-PET has also been shown in MRI negative neuropsychiatric SLE. ${ }^{18}{ }^{33}$ In contrast, one study describes a significant tendency towards lower glucose utilisation only in patients with a high number of white matters lesions found by MRI. ${ }^{31}$ Recently Kao et al compared HMPAO-SPECT and FDG-PET to detect brain involvement in SLE patients and found a higher sensitivity but lower specifity of HMPAO-SPECT. ${ }^{33}$ However, as in the latter study PET scans were interpreted visually instead of a quantitative method as we used, their PET results are not comparable to ours.

In this study FDG-PET hypometabolism was found in at least one brain region of all patients with major or minor CNS symptoms. There were conflicting reports regarding the regions involved in neuropsychiatric SLE: whereas in SPECT studies a variety of abnormal brain regions have been reported (occipital, frontal, temporo-occipital, parietal cortex, basal ganglia and thalamus) $)^{14} 152833$ in FDG-PET scans hypometabolism was mainly found in parietal, temporal, frontotemporal and central regions. ${ }^{17363833}$ In our study the most commonly affected brain region was parieto-occipital, followed by parietal, cerebellar and frontal, whereas temporal areas were rarely involved. Overall in 12 of 23 symptomatic patients and in 8 of 12 patients with normal MRI scans the parieto-occipital region was the only brain region involved. It remains unclear why these lesions were rarely described in previous studies; different scanning techniques may be the reason. One clinical reference to the parieto-occipital region in our patients may be the visual disturbances observed in six patients. Besides visual symptoms no clear correlation could be found between brain glucose utilisation and the topography of the neuropsychological complains. Taken together, our data suggest that the parietooccipital and parietal regions are the most vulnerable zones of the cerebrum in SLE. This may be explained by the location of the parieto-occipital region at the boundary of supply of the major cerebral arteries. However, abnormalities in the parieto-occipital region are not pathognomonic for SLE with neuropsychiatric manifestation: they can also be found in the late whiplash syndrome ${ }^{39}$ or in dementia of the Alzheimer type. ${ }^{40}$

Of particular interest are longitudinal studies in patients with CNS lupus: using SPECT, Falcini et al showed improvement of perfusion alterations in six of seven patients with juvenile SLE. ${ }^{15}$ Kodama et al showed that SPECT changes represent the activity of psychiatric manifestations, ${ }^{41}$ whereas Reiff et al found no correlation of SPECT abnormalities with patient's clinical course. ${ }^{29}$ Few case reports using FDG-PET scans showed a clear correla- 
tion of hypometabolism with clinical conditions, especially with cognitive deficits. ${ }^{363842}$ Accordingly, our follow up data showed amelioration of conspicuous PET findings in 9 of 13 patients. Moreover, the dimension of hypometabolism correlated well with the clinical course of CNS disease, but not with the overall disease activity expressed by SLEDAI score or the serological activity indicator C3d. In six patients improvement of PET findings in association with a marked reduction of SLEDAI score was attributable to changes in immunosuppressive treatment. On the other hand we also observed spontaneous resolution of cognitive dysfunction paralleled by improvement of PET findings in two patients without therapeutic intervention (patients 17 and 18). This phenomenon had also been observed in a recent SPECT study ${ }^{15}$ and might be explained by studies, which have indicated, that subclinical cognitive deficits resolve spontaneously, and do not predict the subsequent emergence of either more profound cognitive deficits or other forms of clinically overt neuropsychiatric SLE. ${ }^{43}$ Persistent hypometabolism of brain areas was observed in seven patients. Cerebral infarcts were underlying these lesions in two patients (patients 4 and 5), and extended white matter lesions in another patient (patient 7). However, persistent deficits in glucose metabolism were also found in patients with normal MRI scans (patient 1, 6, 18). Active and reversible functional brain lesions cannot be differentiated from chronic lesions in a cross sectional PET study. Therefore, longitudinal studies are necessary to clarify the question whether lupus patients may suffer permanent functional brain lesions in the absence of morphological changes and whether such lesions are of clinical relevance.

Abnormalities in functional imaging have also been reported in asymptomatic SLE patients. ${ }^{152830}$ In asymptomatic patients we found unconspicuous PET in three or hypometabolism in singular brain regions in two cases whereas in symptomatic patients multiple brain regions were affected. Both asymptomatic patients with pathological brain PET did not develop cerebral symptoms during follow up. In contrast two patients with major neuropsychiatric symptoms and pathological PET scans had initially normal MRI scans. They subsequently developed a severe CNS exacerbation during which MRI became positive in both (patients 1 and 8). These data suggest that PET positive patients with severe neuropsychiatric symptoms may require intensification of treatment even if MRI is negative. Progress from mild to severe CNS involvement was not observed. However, in most patients immunosuppressive treatment was intensified because of the presence of other disease manifestations. In consideration of prospective data obtained in other studies, ${ }^{43}$ we would suggest that patients with mild symptoms should be monitored carefully but do not require obligatory intensification of treatment.

The pathophysiological mechanisms that underlie the findings in PET scanning may be heterogenous. Depressed glucose utilisation is currently thought to be a result of (1) cerebral atrophy, (2) infarction, (3) reduced density of cells or (4) reduced FDG uptake of cells.

(1) The spatial resolution of current PET scanners does not allow a distinction between cerebrospinal fluid containing spaces and contiguous brain tissue. ${ }^{45}$ Our data suggest that mild atrophy on MRI scan may have no influence on PET findings. However, if cerebral atrophy is moderate or severe, appropriate corrections for atrophy should be used to measure actual brain tissue metabolism more accurately. (2) Multiple infarctions may lead to a patchy pattern in PET, single lesions result in focal deficits of glucose metabolism. Further changes in cerebral metabolism may also occur at intracranial sites distant from ischaemic lesions, a phenomenon known as diaschisis. ${ }^{46}$ Diaschisis is attributed to a decrease in local neuronal activity caused by the loss of afferent projections from the damaged region. A loss of afferent projections may also be the cause of some changes in glucose metabolism seen in patients with white matter lesions. (3) A reduced density of cells as a common cause of hypometabolism in SLE patients seems to be unlikely, because hypometabolism was reversible in most cases. (4) Finally, a reduced FDG uptake of cells may represent either a reversible vascular disorder or a primary abnormality in brain structure. ${ }^{47}$ Widespread and diverse vascular lesions are a pathological hallmark of SLE. Thrombotic lesions would require antiphospholipid antibodies leading to small infarcts. Accordingly, antiphospholipid antibodies have been associated with neurological disorders of vascular origin, ${ }^{48}{ }^{49}$ as seen in some of our patients. In contrast, inflammatory lesions would require either circulating immune complexes or significant complement activation of neutrophils. ${ }^{50}$ In studies on the pathology of cerebral lupus, vasculopathy, infarctions and haemorrhages are often observed, whereas vasculitis is rare. ${ }^{51}$ Otherwise, in lupus patients with CNS involvement a complement mediated vascular injury was described independent from immune complex deposition. ${ }^{52}$ Activation of complement may lead to an occlusive vasculopathy via activation, aggregation and adherance of neutrophils and platelets to vascular endothelium..$^{53}$ However, complement mediated vascular injury does not seem to be the main cause of brain hypometabolism as we were not able to demonstrate a correlation to $\mathrm{C} 3 \mathrm{~d}$ levels or to a consumption of total haemolytic complement.

Antibodies against neuronal structures have been described by several authors in lupus patients, especially in those with organic brain syndromes, psychosis or seizures. ${ }^{389} \mathrm{We}$ screened patients sera for the presence of antibodies against beef brain tissue (anti-CNS) by a well established method. ${ }^{9}$ Interestingly, we found a correlation between anti-CNS antibodies and the presence of severe and to a lesser extent with mild neuropsychiatric symptoms. Antibodies against ribosomal P protein, an intracytoplasmic constituent of neuronal and other human cells, were reported to be highly specific for psychosis, ${ }^{64}$ or depression in 
lupus patients. ${ }^{655}$ The specificity of antiribosomal $\mathrm{P}$ antibodies to lupus psychosis or depression was not confirmed by other studies. ${ }^{5657}$ We found only a weak association between anti-ribosomal $\mathrm{P}$ antibodies and mood disorders, but a statistically significant correlation with the presence of overall psychiatric symptoms (including reactive depression and neurosis). The discrepancy between our findings and those by others ${ }^{65}$ might be influenced by different assays used to detect anti-ribosomal $\mathrm{P}$ antibodies or by the small number of patients included in our study. The role of autoantibodies against neuronal cell constituents in the pathogenesis of cerebral SLE is unclear. It is assumed that autoantibodies exert their effects by interfering with the cell's ability as a responder in the neuronal network. ${ }^{58}$ Microvascular injury induced by immune complexes, complement or antiphospholipid antibodies may change the bloodbrain barrier and provide access of systemically produced antibodies that would otherwise not reach the CNS. However, we were not able to demonstrate any significant association between the PET or MRI findings and presence of distinct autoantibodies. Moreover, we observed brain glucose hypometabolism also in three patients (17, 18 and 24) without antibodies against cardiolipin, CNS tissue, ribosomal $\mathrm{P}$ protein or signs of complement consumption.

Finally, cytokines may play a part in the development of functional brain lesions seen in PET. Intrathecal synthesis of interferon $\alpha^{59}$ and interleukin $6^{60}$ has been reported in neuropsychiatric lupus. Interestingly, in a recent study changes in brain glucose metabolism have been demonstrated in patients with chronic viral hepatitis during treatment with interferon $\alpha .{ }^{61}$ This issue requires further study.

We conclude that the combination of PET and MRI constitutes the most useful diagnostic procedure to differentiate functional from morphological changes in CNS involvement of SLE. While MRI scans are highly sensitive in detecting infarction and especially white matter lesions, we suggest that brain PET is primarily indicated in patients with cerebral symptoms and unconspicuous MRI. In these patients FDG-PET may establish the diagnosis of CNS involvement and monitor the brain function. Despite lack of specificity, PET may also be helpful in diagnosis of unclear cases, when only few ACR criteria and minor neuropsychiatric symptoms are present.

SMW and AO contributed equally to the article.

1 Neuwelt CM, Lacks S, Kaye BR, Ellman JB, Borenstein DG. Role of intravenous cyclophosphamide in the treatment of severe neuropsychiatric systemic lupus erythematosus. Am J Med 1995;98:32-41.

2 Ellis SG, Verity MA. Central nervous system involvement in systemic lupus erythematosus: a review of neuropathologic findings in 57 cases, 1955-1977. Semin Arthritis Rheum 1979;8:212-21.

3 How A, Dent PB, Liao SK, Denburg JA. Antineuronal antibodies in neuropsychiatric systemic lupus erythematosus. Arthritis Rheum 1985;28:789-95.

4 Long AA, Denburg SD, Carbotte RM, Singal DP, Denburg JA. Serum lymphocytotoxic antibodies and neurocognitive function in systemic lupus erythematosus. Ann Rheum Dis 1990;49:249-53.
5 Sibley JT, Olszynski WP, Decoteau WE, Sundaram MB. The incidence and prognosis of central nervous system dis1992;19:47-52.

6 Schneebaum AB, Singleton JD, West SG, Blodgett JK, Allen LG, Cheronis JC, et al. Association of psychiatric manifestations with antibodies to ribosomal $\mathrm{P}$ proteins in systemic lupus erythematosus. Am J Med 1991;90:54-62. 7 Bluestein HG. Neurocytotoxic antibodies in serum of Acad Sci U S A 1978;75:3965-9.

8 Diederichsen H, Pyndt IC. Antibodies against neurons in a patient with systemic lupus erythematosus, cerebral palsy, and epilepsy. Brain 1970;93:407-12.

9 Klein R, Richter C, Berg PA. Antibodies against central nervous system tissue (anti-CNS) detected by ELISA and western blotting: marker antibodies for neuropsychiatric western blotting: marker antibodies for neuropsychiatric
manifestations in connective tissue diseases. Autoimmunity manifestations in

10 Teh L, Isenberg DA. Antiribosomal P protein antibodies in systemic lupus erythematosus. Arthritis Rheum 1994;37: $307-15$.

11 Stimmler MM, Coletti PM, Quismorio FP Jr. Magnetic resonance imaging of the brain in neuropsychiatric systemic lupus erythematosus. Semin Arthritis Rheum 1993;22:335-49.

12 West SG, Emlen W, Wener MH, Kotzin BL. Neuropsychiatric lupus erythematosus: a 10-year prospective study on the value of diagnostic tests. Am J Med 1995;99:153-63.

13 Kozora E, West SG, Kotzin BL, Julian L, Porter S, Bigler E. Magnetic resonance imaging abnormalities and cognitive deficits in systemic lupus erythematosus patients without overt central nervous system disease. Arthritis Rheum overt central

14 Kovacs JA, Urowitz MB, Gladman DD, Zeman R. The use of single photon emission computerized tomography in neuropsychiatric SLE: a pilot study. J Rheumatol 1995;22:
1247-53.

15 Falcini F, De Cristofaro MT, Ermini M, Guarnieri M, Massai G, Olmastroni $M$, et al. Regional cerebral blood flow in juvenile systemic lupus erythematosus: a prospective SPECT study. Single photon emission computed tomography. J Rheumatol 1998;25:583-8.

16 Meyer GJ, Schober O, Stoppe G, Wildhagen K, Seidel JW, Hundeshagen $\mathrm{H}$. Cerebral involvement in systemic lupus erythematosus (SLE): comparison of positron emission tomography (PET) with other imaging methods. Psychiatry Res 1989;29:367-8.

17 Stoppe G, Wildhagen K, Seidel JW, Meyer GJ, Schober O, Heintz P, et al. Positron emission tomography in neuropsychiatric lupus erythematosus. Neurology 1990;40:304-8.

18 Otte A, Weiner SM, Peter HH, Mueller-Brand J, Goetze M, Moser E, et al. Brain glucose utilization in systemic lupus erythematosus with neuropsychiatric symptoms: a controlled positron emission tomography study. Eur J Nucl Med 1997;24:787-91.

19 Grunwald F, Schomburg A, Badali A, Ruhlmann J, Pavics L, Biersack HJ. 18FDG PET and acetazolamide-enhanced $99 \mathrm{mTc}$-HMPAO SPET in systemic lupus erythematosus. Eur J Nucl Med 1995;22:1073-7.

20 Tan EM, Cohen AS, Fries JF, Masi AT, McShane DJ, Rothfield NF, et al. The 1982 revised criteria for the classification of systemic lupus erythematosus. Arthritis Rheum 1982;25:1271-7.

21 Bombardier C, Gladman DD, Urowitz MB, Caron D, Chang CH. Derivation of the SLEDAI. A disease activity index for lupus patients. The Committee on Prognosis Studies in SLE. Arthritis Rheum 1992;35:630-40.

22 ACR Ad Hoc Committee on Neuropsychiatric Lupus nomenclature. The American College of Rheumatology nomenclature and case definitions for neuropsychiatric lupus syndromes. Arthritis Rheum 1999;42:599-608

23 Hamacher K, Coenen HH, Stocklin G. Efficient stereospecific synthesis of no-carrier-added 2-[18F]-fluoro-2-deoxyD-glucose using aminopolyether supported nucleophilic substitution. J Nucl Med 1986;27:235-8.

24 Huang SC, Carson R, Phelps M, Hoffman E, Schelbert H, Kuhl D. A boundary method for attenuation correction in positron emission tomography. IEEE Trans Nucl Sci 1981; 22:627-37.

25 Rother E, Lang B, Coldewey R, Hartung K, Peter HH. Complement split product $\mathrm{C} 3 \mathrm{~d}$ as an indicator of disease activity in systemic lupus erythematosus. Clin Rheumatol 1993;12:31-5.

26 Kushner MJ, Chawluk J, Fazekas F, Mandell B, Burke A, Jaggi J, et al. Cerebral blood flow in systemic lupus erythematosus with or without cerebral complications. Neurology 1987;37:1596-8.

27 Awada HH, Mamo HL, Luft AG, Ponsin JC, Kahn MF. Cerebral blood flow in systemic lupus erythematosus with and without central nervous system involvement. J Neurol Neurosurg Psychiatry 1987;50:1597-601.

28 Rubbert A, Marienhagen J, Pirner K, Manger B, Grebmeier J, Engelhardt A, et al. Single-photon-emission computed tomography analysis of cerebral blood flow in the evaluation of central nervous system involvement in patients with systemic lupus erythematosus. Arthritis Rheum 1993;36:1253-62.

29 Reiff A, Miller J, Shaham B, Bernstein B, Szer IS. Childhood central nervous system lupus; longitudinal assessment using single photon emission computed tomogassessment using single photon emission
raphy. J Rheumatol 1997;24:2461-5.

30 Emmi L, Bramati M, De Cristofaro MT, Mascalchi M, Dal Pozzo G, Marconi GP, et al. MRI and SPECT investiga- 
tions of the CNS in SLE patients. Clin Exp Rheumatol 1993;11:13-20.

31 Sailer M, Burchert W, Ehrenheim C, Smid HG, Haas J, Wildhagen $\mathrm{K}$, et al. Positron emission tomography and magnetic resonance imaging for cerebral involvement in patients with systemic lupus erythematosus. J Neurol 1997;244:186-93.

32 Chinn RJ, Wilkinson ID, Hall-Craggs MA, Paley MN, Shortall E, Carter S, et al. Magnetic resonance imaging of the brain and cerebral proton spectroscopy in patients with systemic lupus erythematosus. Arthritis Rheum 1997;40: 36-46.

33 Kao C-H, Ho Y-J, Lan J-L, Changlai S-P, Liao K-K, Chieng P-U. Discrepancy between regional cerebral blood flow and glucose metabolism of the brain in systemic lupus erythematosus patients with normal brain magnetic resonance imaging findings. Arthritis Rheum 1999;42: $61-8$.

34 Higashi K, Nishikawa T, Seki H, Oguchi $M$, Nambu Y, Ueda Y, et al. Comparison of fluorine-18-FDG PET and
thallium-201 SPECT in evaluation of lung cancer. J Nucl Med 1998;39:9-15.

35 Otte A, Ettlin TM, Nitzsche EU, Wachter K, Hoegerle S, Simon GH, et al. PET and SPECT in whiplash syndrome: a new approach to a forgotten brain? J Neurol Neurosurg Psychiatry 1997;63:368-72.

36 Carbotte RM, Denburg SD, Denburg JA, Nahmias C, Garnett ES. Fluctuating cognitive abnormalities and cerebral glucose metabolism in neuropsychiatric systemic lupus erythematosus. J Neurol Neurosurg Psychiatry 1992;55: 1054-9.

37 Csepany T, Gulyas B, Tron L, Szakall S, Kiss E, Kollar J, et al. Cerebral positron emission tomographic study in systemic lupus erythematosus. Orv Hetil 1997;138:194752 .

38 Hiraiwa $\mathrm{M}$, Nonaka C, Abe T, Iio M. Positron emission tomography in systemic lupus erythematosus: relation of
cerebral vasculitis to PET findings. AJNR Am J Neuroracerebral vasculitis to
diol $1983 ; 4: 541-3$.

39 Otte A, Mueller-Brand J, Fierz L. Brain SPECT findings in late whiplash syndrome. Lancet 1995;345:1513.

40 Waldemar G, Bruhn P, Kristensen M, Johnsen A, Paulson $\mathrm{OB}$, Lassen NA. Heterogeneity of neocortical cerebral blood flow deficits in dementia of the Alzheimer type: a [99mTc]-d,1-HMPAO SPECT study. J Neurol Neurosurg Psychiatry 1994;57:285-95.

41 Kodama K, Okada S, Hino T, Takabayashi K, Nawata Y, Uchida Y, et al. Single photon emission computed tomography in systemic lupus erythematosus with psychiatric symptoms. J Neurol Neurosurg Psychiatry 1995;58:30711 .

42 Otte A, Weiner SM, Hoegerle S, Wolf R, Juengling FD, Peter $\mathrm{HH}$, et al. Neuropsychiatric systemic lupus erythematosus before and after immunosuppressive treetment: a FDG PET study. Lupus 1998;7:57-9.

43 Hanly JG, Cassell K, Fisk JD. Cognitive function in systemic lupus erythematosus: results of a 5-year prospective study. Arthritis Rheum 1997;40:1542-3.

44 Hay EM, Huddy A, Black D, Mbaya P, Tomenson B, Bernstein RM, et al. A prospective study of psychiatric disorder and cognitive function in systemic lupus erythematosus. Ann Rheum Dis 1994;53:298-303.

45 Chawluk JB, Alavi A, Dann R, Hurtig HI, Bais S, Kushner MJ, et al. Positron emission tomography in aging and dementia: effect of cerebral atrophy. J Nucl Med 1987;28: 431-7.

46 Feeney DM, Baron JC. Diaschisis. Stroke 1986;17:817-30.

47 Hanly JG. Single photon emission computed tomography scanning in neuropsychiatric systemic lupus erythematosus. J Rheumatol 1998;25:401-3.

48 Briley DP, Coull BM, Goodnight SH, Jr. Neurological disease associated with antiphospholipid antibodies. Ann Neurol 1989;25:221-7.

49 Levine SR, Welch KM. The spectrum of neurologic disease associated with antiphospholipid antibodies: Lupus anticoagulants and anticardiolipin antibodies. Arch Neurol 1987; $44: 876-83$

50 Belmont HM, Abramson SB, Lie JT. Pathology and pathogenesis of vascular injury in systemic lupus erythematosus: Interactions of inflammatory cells and activated endothelium. Arthritis Rheum 1996;39:9-22.

51 van Dam AP. Diagnosis and pathogenesis of CNS lupus. Rheumatol Int 1991;11:1-11.

52 Hopkins P, Belmont HM, Buyon J, Philips M, Weissmann $\mathrm{G}$, Abramson SB. Increased levels of plasma anaphylatoxins in systemic lupus erythematosus predict flares of the disease and may elicit vascular injury in lupus cerebritis. disease and may elicit vascular injury
Arthritis Rheum 1988;31:632-41.

53 Abramson SB, Weissmann G. Complement split products and the pathogenesis of SLE. Hosp Prac 1988;23:45-56.

54 Bonfa E, Golombek SJ, Kaufman LD, Skelly S, Weissbach $\mathrm{H}$, Brot $\mathrm{N}$, et al. Association between lupus psychosis and anti-ribosomal $\mathrm{P}$ protein antibodies. $\mathrm{N}$ Engl J Med 1987;317:265-71.

55 Arnett FC, Reveille JD, Moutsopoulos HM, Georgescu L, Elkon KB. Ribosomal P autoantibodies in systemic lupus erythematosus: Frequencies in different ethnic groups and clinical and immunogenetic associations. Arthritis Rheum 1996;39:1833-9.

56 Teh LS, Bedwell AE, Isenberg DA, Gordon C, Emery P, Charles PJ, et al. Antibodies to protein P in systemic lupus Charles PJ, et al. Antibodies to protein P in system
erythematosus. Ann Rheum Dis 1992;51:489-94.

57 Van Dam A, Nossent H, de Jong J, Meilof J, ter Borg E-J, Swaak T, et al. Diagnostic value of antibodies against ribosomal phosphoprotiens: a cross sectional and longitudinal study. J Rheumatol 1991;18:1026-34.

58 Bruyn GAW. Controversies in lupus: nervous system involvement. Ann Rheum Dis 1995; 54:159-67.

59 Shiozawa S, Kuroki Y, Kim M, Hirohata S, Ogino T. Interferon-alpha in lupus psychosis. Arthritis Rheum 1992; 35:417-22.

60 Hirohata S, Miyamoto T. Elevated levels of interleukin-6 in cerebrospinal fluid from patients with systemic lupus erythematosus and central nervous system involvement. Arthritis Rheum 1990; 33:644-9.

61 Jüngling FD, Lieb K, Gut O, Bauer J, Moser E, Nitzsche EU. FDG-PET zum Nachweis IFN-alpha assoziierter zerebraler Glukosestoffwechselstörungen. Nuklearmedizin zerebraler Gluk 38:A21. 